\title{
Desempenho agronômico da cultura da soja em diferentes arranjos espaciais ${ }^{1}$
}

\author{
Claudia Klein \\ Universidade do Oeste de Santa Catarina \\ (UNOESC - Campus São José do Cedro) \\ (klein811@hotmail.com) \\ Cesar Olmar Meurer \\ Universidade do Oeste de Santa Catarina \\ (UNOESC - Campus São José do Cedro) \\ (cesarmeurer2015@gmail.com) \\ Everton Luan Schneider \\ Universidade do Oeste de Santa Catarina \\ (UNOESC - Campus São José do Cedro) \\ (schneideeverton@gmail.com) \\ Odirlei Soldá \\ Universidade do Oeste de Santa Catarina \\ (UNOESC - Campus São José do Cedro) \\ (solda_odi@hotmail.com) \\ Marcelo Henrique Daneluz \\ Universidade do Oeste de Santa Catarina \\ (UNOESC - Campus São José do Cedro) \\ (marcelodaneluz@gmail.com)
}

Resumo: O presente estudo teve por objetivo avaliar arranjos espaciais na cultura da soja, no município de Anchieta (SC). O delineamento experimental utilizado foi de blocos casualizados com cinco repetições e quatro tratamentos $(0,60 \mathrm{~m}, 0,45 \mathrm{~m}, 0,30 \mathrm{~m}$ e 0,20 x 0,40 m-fileiras duplas), utilizando a cultivar AMS Tibagi RR. Avaliou-se a altura de inserção da primeira vagem, massa de mil grãos, produtividade real e potencial. Os dados foram submetidos à análise de variância pelo teste $\mathrm{F}$ e quando significativos, comparados pelo teste de Tukey a $5 \%$ de probabilidade de erro. A cultura da soja submetida a diferentes arranjos espaciais não apresentou diferença estatística para as variáveis produtividade real, potencial e massa de mil grãos. A diferença estatística foi constatada para a variável altura de inserção da primeira vagem, sendo que, quanto mais próximos os espaçamentos, maior a altura de inserção da primeira vagem. Portanto, diferentes espaçamentos não influenciam a produtividade de grãos de soja.

Palavras-chave: Espaçamento; Produtividade; População de plantas.

\section{Agronomic performance of soybean in different spatial arrangements}

Abstract: This study aimed to evaluate spatial arrangements in soybean culture, in Anchieta - SC. The experimental design used was the randomized blocks with five repetitions and four treatments $(0.60 \mathrm{~m}$, $0.45 \mathrm{~m}, 0.30 \mathrm{~m}$ and $0.20 \times 0.40 \mathrm{~m}$ - double rows), using the cultivar AMS Tibagi RR. We evaluated the first soybean pod height, thousand-grain mass, real productivity and potential. The data were submitted to analysis of variance by $\mathrm{F}$ test and when significant, compared to the Tukey test at $5 \%$ failure probability. The soybean culture submitted to different spatial arrangements did not present statistical

\footnotetext{
${ }^{1}$ Parte do Trabalho de Curso apresentando ao Curso de Agronomia da Universidade do Oeste de Santa Catarina, Campus Aproximado de São José do Cedro (SC), como pré-requisito parcial à obtenção do título de Bacharel em Agronomia.
} 
difference for the variables of real productivity, potential and thousand-grain mass. The statistical difference was found for the variable height of the first soybean pod, and the closer the spacing, the greater will be the first pod height. Therefore, different spacing do not influence the productivity of soybeans.

Keywords: spacing; productivity; plant population.

\section{INTRODUÇÃO}

A produtividade das culturas é definida pela interação entre planta, ambiente e manejo (CRUZ et al., 2016). O espaçamento adequado na semeadura da soja é um fator a ser considerado para que obtenha alta produtividade de grãos, pois uma simples variação nos limites de espaçamento entre fileiras e densidade de fileiras pode afetar diversos fatores no desenvolvimento das plantas (SEDIYAMA, 1985).

Nas condições de maiores densidades de plantas, assim como ocorre com o aumento do espaçamento entrelinhas, a competição pelos recursos do meio será elevada. A densidade de semeadura é fator determinante para o arranjo das plantas no ambiente de produção e influencia o crescimento da soja, interfere na competição por recursos do solo, especialmente água e nutrientes, proporcionando mudanças morfofisiológicas nas plantas (ARGENTA et al., 2001).

Em semeaduras em que 0 aumento da população de plantas na linha causa efeito acentuado no acamamento das plantas, altas populações podem ocasionar a diminuição no rendimento de grãos. Conforme Schidlowski (2012), em função de a soja apresentar período vegetativo mais longo nas regiões de clima temperado do que nas regiões mais quentes, as plantas apresentam maior crescimento em altura e, também por isso, tem-se efeito acentuado no acamamento.

Este trabalho teve por objetivo determinar se os arranjos espaciais influenciam no rendimento da cultura da soja.

\section{MATERIAL E MÉTODOS}

O estudo foi realizado na safra 2015/16, na Linha Camargo, zona rural do município de Anchieta - SC, 26²7'30" S 5315'25" W com altitude média de $858 \mathrm{~m}$ (GOOGLE EARTH PRO, 2014). 
O clima caracteriza-se como Cfa - Clima Temperado úmido com verão quente e chuva durante todos os meses do ano (MOTA et al., 1970), com temperaturas do mês mais quente superior a $\pm 22^{\circ} \mathrm{C}$, e temperaturas médias no mês mais frio inferior $\mathrm{a} \pm 18 \stackrel{\circ}{ } \mathrm{C}$, A precipitação durante a condução do experimento com a cultura do soja foi $1460 \mathrm{~mm}$, média diária de $10 \mathrm{~mm}$. O solo da área é classificado como LATOSSOLO Vermelho (EMBRAPA, 2013) com relevo plano e área manejada com sistema de plantio direto a 10 anos, com sucessão de aveia e azevém no inverno, milho e soja no verão. A dessecação da área foi realizada 30 dias antes da semeadura com herbicida glifosato potássico equivalente $500 \mathrm{~g} \mathrm{~L}^{-1}$ na dosagem de $1,5 \mathrm{~L} \mathrm{ha}^{-1}$ para $500 \mathrm{~mL} \mathrm{ha}^{-1}$ de calda. As sementes foram adquiridas com tratamento comercial de fungicida do grupo carbendazim com a dosagem de $2 \mathrm{~mL} \mathrm{~kg}$ de semente mais inseticida do grupo Neonicotinoide, Metilcarbamato de Oxina na dosagem de $3 \mathrm{~mL} \mathrm{~kg}$ de semente.

A semeadura foi realizada foi no sistema de plantio direto, com a cultivar AMS Tibagi RR, do grupo de maturação super precoce e hábito de crescimento semideterminado, implantado em novembro de 2015, seguindo o zoneamento agroclimático.

Sendo que a semeadura foi realizada manualmente, com auxílio de uma régua de madeira furada para colocar as sementes nos espaçamentos adequados por parcela de 60, 45, 30 e 20x40 cm (fileira dupla), considerando uma população de 300 mil plantas ha-1, 432 plantas por parcela. Obtendo no espaçamento de $60 \mathrm{~cm}$ entre fileiras, 18 sementes por metro linear, no espaçamento de $45 \mathrm{~cm}, 13,5$ sementes por metro linear, no espaçamento de $30 \mathrm{~cm}, 9$ sementes por metro linear e no espaçamento de 20x40 cm (fileiras duplas) 9 sementes por metro linear.

As adubações de base foram realizadas com base no manual de adubação e calagem (SBCS, 2004), para uma expectativa de rendimento de $3600 \mathrm{~kg} \mathrm{ha}^{-1}$, formulação 0-20-20 na quantidade de $470 \mathrm{~kg} \mathrm{ha}^{-1}$, totalizando $0,677 \mathrm{~kg}$ por parcela, na linha de semeadura.

Devido à ocorrência de planta daninha, foi necessário o controle das mesmas, o controle foi realizado 28 dias após o plantio com um herbicida glifosato potássico, equivalente $500 \mathrm{~g} / \mathrm{L}$ na dosagem de $1,5 \mathrm{~L} \mathrm{ha}^{-1}$.

Os tratamentos fitossanitários foram realizados de forma preventiva em intervalos de aplicação de 16 a 18 dias, observado o período residual do produto, conforme bula do fabricante, foi realizado o controle fúngico para oídio com o produto 
Blatlle, fungicida sistêmico do grupo dos Triazol e Bendamidazol, nas dosagens de $0,050 \mathrm{~g} \mathrm{ha}^{-1}$ de ingrediente ativo (i.a).

Os tratamentos fúngicos foram realizados preventivamente utilizando osprincípios ativos, Flutiazol, Carbendazim, Azoxistribina, Estroburulina, Benzovindiflupir, Estroburulina, Triazolinthione, para o controle da ferrugem asiática, juntamente com estas aplicações foi realizado o controle das lagartas com inseticida de contato e ingestão do grupo químico Organofosforado na dosagem de $0,720 \mathrm{~g}$ ha-1 de i.a., e Benzoilureia na dosagem de 0,015 $\mathrm{g} \mathrm{ha}^{-1}$ de i.a.. Foram adicionados adjuvantes para melhoria da eficiência da calda e redução da deriva. As aplicações foram realizadas com máquina tratorizada, com quantidade de calda de $150 \mathrm{~L} \mathrm{ha}{ }^{-1}$.

A colheita foi realizada quando a cultivar atingiu o ponto de maturação fisiológica no estádio R8, a coleta do material foi de forma manual em abril de 2015, sendo coletadas 10 plantas por parcela. Para a estimativa da produtividade real por hectare foram contados o número de grãos da amostra de cada parcela, realizado média e extrapolado para as 300.000 plantas (área total). A massa de 1000 grãos foi realizada conforme o manual de regras para análise de sementes (BRASIL, 2009). Para determinação do rendimento potencial determinou-se o número de grãos falhos por legume das 10 plantas de cada unidade experimental (FÁVERO \& LANA, 2014). A altura de inserção da primeira vagem foi medida a partir nível da superfície do solo.

Os dados foram submetidos a análise de variância pelo teste $F$ e quando significativos, comparados pelo teste de Tukey a $5 \%$ de probabilidade de erro utilizando o software Sisvar (FERREIRA, 2011).

\section{RESULTADOS E DISCUSSÕES}

A altura de inserção de primeira vagem foi influenciada pelo espaçamento utilizado (Gráfico 1), quanto mais próximo o espaçamento entre fileiras maior a altura de inserção da primeira vagem na haste principal. Para Potafós (2000), a soja cultivada em altas densidades aumenta a competição por luminosidade, favorecendo o aumento da altura das plantas e consequentemente a atura de inserção da primeira vagem. 
Em trabalho com vários espaçamento entre fileiras e densidade nas fileiras de semeadura, Sediyama (2009) verificou que o crescimento da planta é afetado, principalmente a altura de inserção da primeira vagem, sendo que com maiores espaçamentos a planta tende a possuir menor estatura e por consequência menor altura de inserção da primeira vagem e quando ocorre a diminuição do espaçamento e aumento da densidade de plantas na fileira a tendência é que aumente a altura de inserção da primeira vagem. Cruz et al. (2016) e Balbinot Junior et al. (2015) relatam que a atura de inserção da primeira aumenta paralelamente como o aumento da densidade de semeadura.

Gráfico 1:Altura de inserção da primeira vagem $(\mathrm{cm})$ de soja na haste principal em função dos espaçamentos de $60 \mathrm{~cm}$ (T1), $45 \mathrm{~cm}$ (T2), $30 \mathrm{~cm}$ (T3) e $20 \mathrm{~cm}$ x $40 \mathrm{~cm}$ (T4). São José do Cedro, SC, 2016

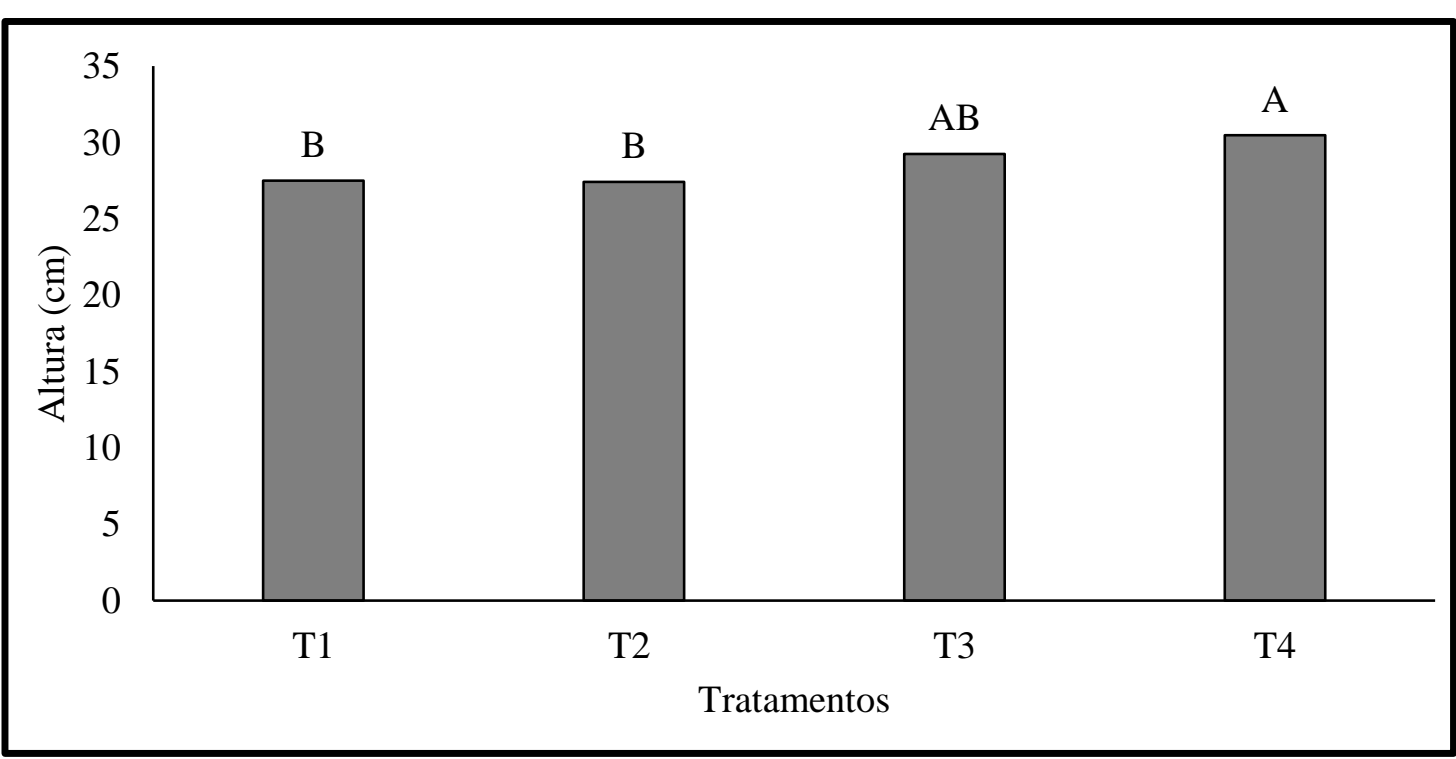

Fonte: Os autores (2016)

Médias seguidas de mesma letra não diferiram significativamente pelo teste Tukey a $5 \%$ de probabilidade de erro. Coeficiente de variação: 4,99\%. Diferença mínima significativa: $2,68 \mathrm{~cm}$.

A massa de mil grãos não diferiu em função aos diferentes tratamentos (Gráfico 3). Conforme Silva (2015), por ser uma característica genética de alta herdabilidade, é influenciada apenas pela cultivar de soja.

Para Balbinot Junior et al. (2015) e Heiffig (2006), a massa de mil grãos, apesar de ser importante na determinação da produtividade, tente a não ser influenciada pela 
densidade de semeadura, mas, por outros fatores como a precipitação no período de enchimento de grãos, doenças foliares e genética da planta.

Gráfico 2: Massa de mil grãos (g) de soja em função dos espaçamentos de $60 \mathrm{~cm}$ (T1), 45 cm (T2), 30 cm (T3) e 20 cm x 40 cm (T4). São José do Cedro, SC, 2016

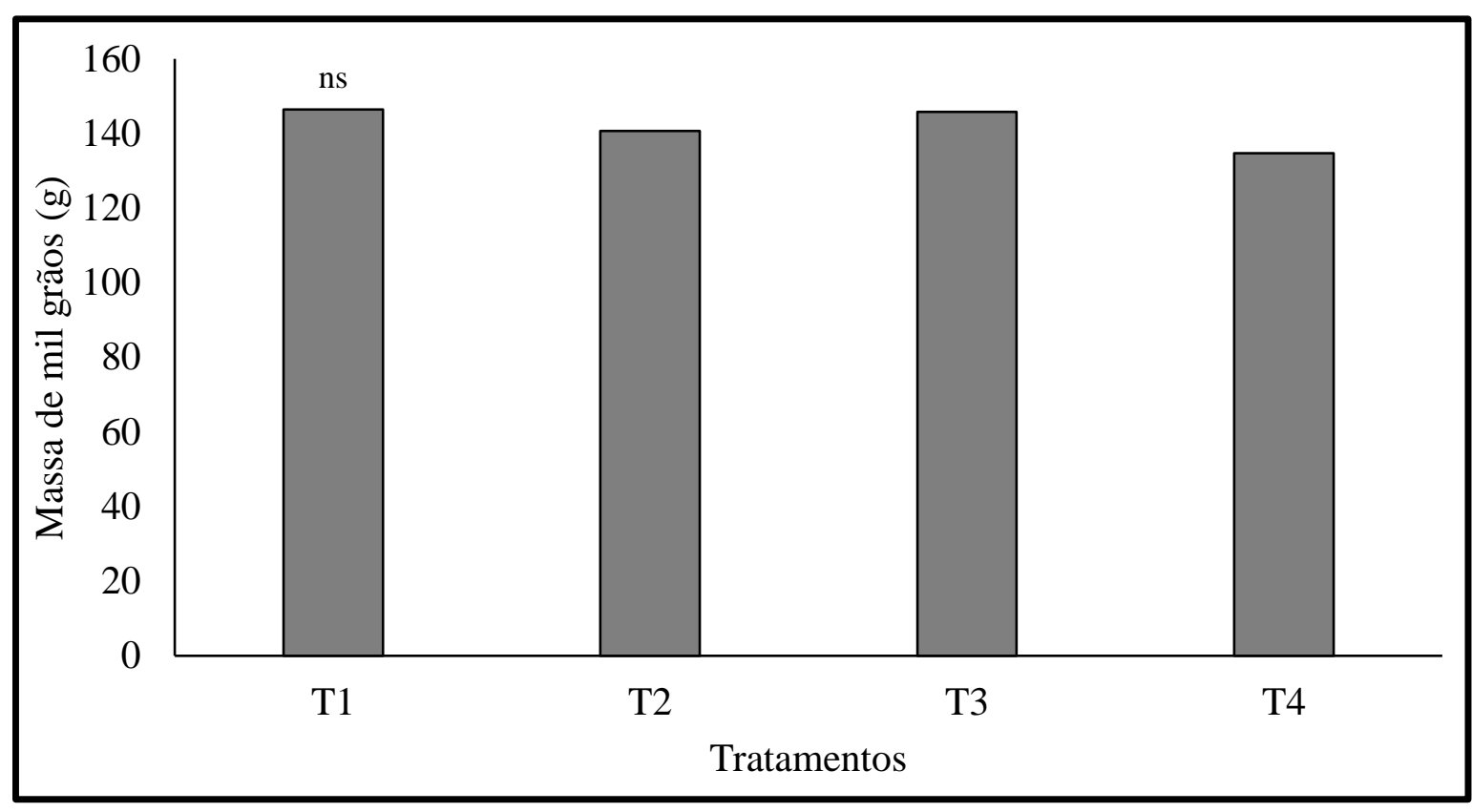

Fonte: Os autores (2016)

Diferenças não significativas pelo teste Tukey a $5 \%$ de probabilidade de erro. Coeficiente de variação: 8,26\%. Diferença mínima significativa: $22 \mathrm{~g}$.

$\mathrm{Na}$ análise da produtividade potencial, observou-se que se todas as condições edafoclimáticas, tais como temperatura, precipitação, entre outras, estivessem dentro das condições ideais para o desenvolvimento da soja, a cultura poderia ter expressado valores de produtividade diferentes dos quais foram obtidas, sendo possível observar essa diferença no gráfico 3.

A produtividade, tanto real quanto potencial, não diferiu estatisticamente em relação a diferentes espaçamentos (Gráfico 3). Resultados semelhantes foram obtidos por Cruz et al. (2016), Heiffig et al. (2006), Balbinot Junior (2014) e Oliveira Junior (2013), que também observaram que a cultura não tem a produtividade afetada pelos diferentes espaçamentos entrelinha, e inferem esse resultado a grande plasticidade fenotípica da cultura, ou seja, sua grande capacidade em se adaptar aos diferentes arranjos. 
Gráfico 3: Produtividade real e produtividade potencial $\left(\mathrm{kg} \mathrm{ha}^{-1}\right)$ da soja em função dos espaçamentos de $60 \mathrm{~cm}$ (T1), $45 \mathrm{~cm}$ (T2), $30 \mathrm{~cm}$ (T3) e $20 \mathrm{~cm}$ x $40 \mathrm{~cm}$ (T4). São José do

Cedro, SC, 2016

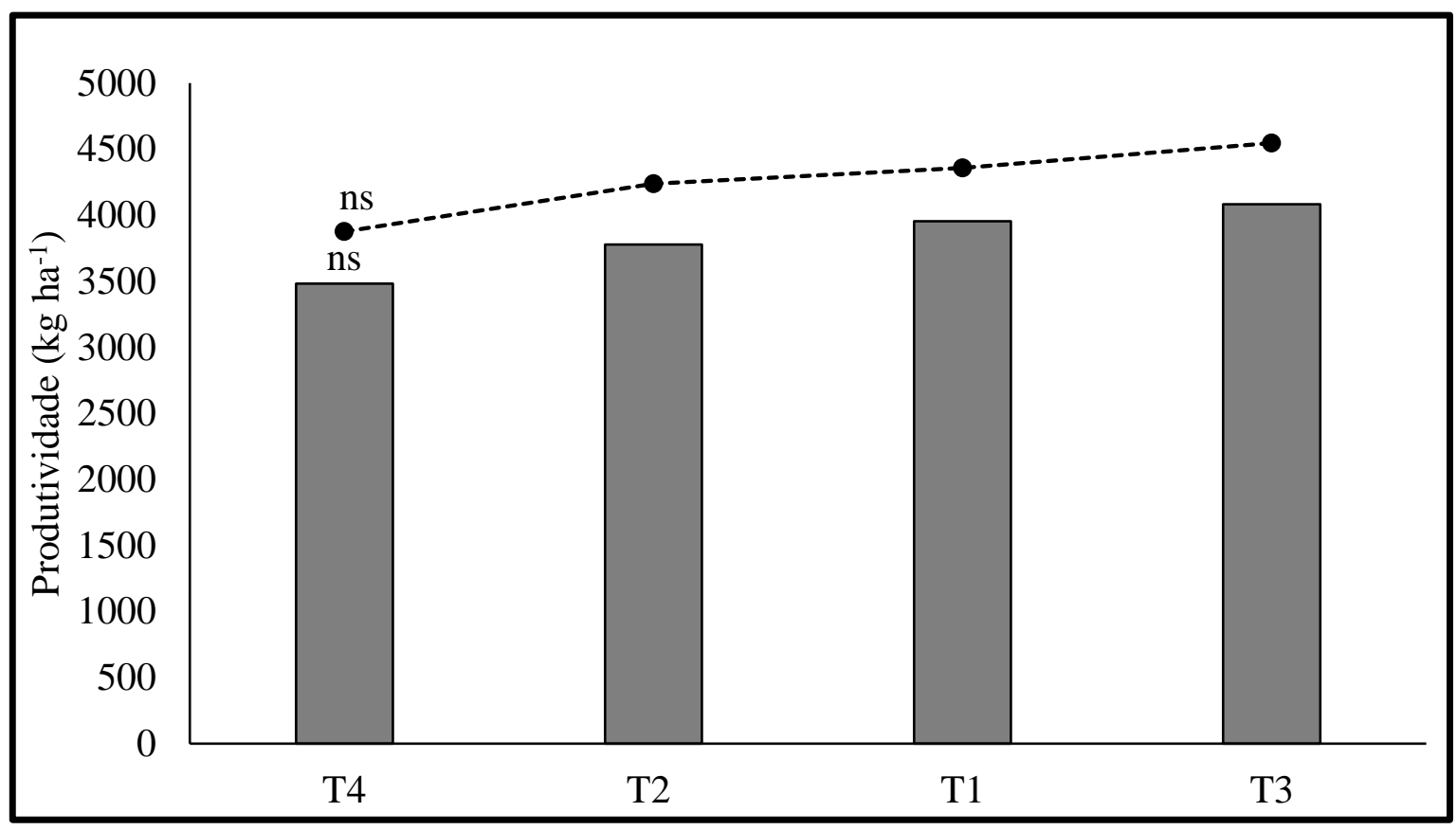

Tratamentos

$\square$ Produtividade --๑--·Produtividade potencial

Fonte: Os autores (2016)

Diferenças não significativas pelo teste Tukey a $5 \%$ de probabilidade de erro. Produtividade: coeficiente de variação: 12,59\%. Diferença mínima significativa: 904,35 $\mathrm{kg} \mathrm{ha}^{-1}$. Produtividade potencial: coeficiente de variação: 10,75\%. Diferença mínima significativa: $858,88 \mathrm{~kg} \mathrm{ha}^{-1}$.

Entretanto, Procópio et al. (2014) constataram que ocorre diminuição da produtividade quando a semeadura ocorre com espaçamento reduzido e a semeadura em fileiras duplas proporciona resultados similares aos obtidos com espaçamentos tradicionais utilizados na cultura, e a densidade de grãos não interfere na produtividade independentemente do espaçamento entrelinhas.

Para uma análise econômica, foram considerados os mesmos custos para todos os tratamentos (Tabela 1) e a média dos tratamentos para os valores de produtividade, onde constatou-se a diferença de produtividade entre os tratamento,

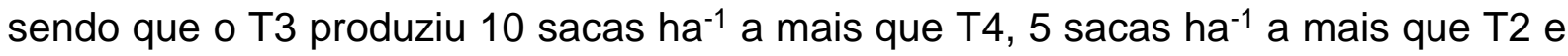
2 sacas $\mathrm{ha}^{-1}$ a mais que $\mathrm{T} 1$. Observou-se uma amplitude entre as produtividades 
máxima e mínima de $601 \mathrm{~kg} \mathrm{ha}^{-1}$ e uma média aritmética, que é a média das produtividades de $3824,18 \mathrm{~kg} \mathrm{ha}^{-1}$ ou 63,73 sacas.

Tabela 1: Análise descritiva da produtividade, considerando o valor médio dos tratamentos de $60 \mathrm{~cm}$ (T1), $45 \mathrm{~cm}$ (T2), $30 \mathrm{~cm}$ (T3) e $20 \mathrm{~cm}$ x $40 \mathrm{~cm}$ (T4). São José do Cedro, SC, 2016

\begin{tabular}{|c|c|c|}
\hline Parâmetro da análise descritiva & $\mathrm{kg} \mathrm{ha}^{-1}$ & Tratamento \\
\hline Valor mínimo & 3482 & T4 \\
\hline Valor máximo & 4083 & T3 \\
\hline Amplitude (máx-min) & 601 & - \\
\hline Média aritmética & 3824,18 & \\
\hline
\end{tabular}

Fonte: Os autores (2016).

Assim, o espaçamento de 0,30 m entre fileiras (T3) foi o mais rentável dentre os espaçamentos avaliados neste estudo, devido ter maior produtividade que os demais tratamentos, com os mesmos tratos culturais.

\section{CONCLUSÃO}

A utilização de diferentes arranjos espaciais não afeta a produtividade de grãos, e massa de mil grãos, para o cultivar de soja AMS Tibagi RR.

A altura de inserção da primeira vagem alterou com o arranjo espacial, sendo que, quanto maior o espaçamento, menor a altura de inserção da primeira vagem, e quanto menor o espaçamento, maior a altura de inserção da primeira vagem.

\section{REFERÊNCIAS}

ARGENTA, Gilber; SILVA, Paulo Regis Ferreira; SANGOL, Luís. Arranjo de plantas em milho: análise do estado-da-arte. Ciência Rural, Santa Maria, v.31, n.6, p.1075-1084, 2001.

BALBINOT JUNIOR, A. A. et al. Circular técnica 106: Redução do espaçamento entre linhas na cultura da soja. Londrina, PR. 2014. 8p.

BALBINOT JUNIOR, A. A. et al. Documentos 364: Densidade de plantas na cultura da soja. Londrina, PR. 2015. 38p.

BRASIL. Ministério da Agricultura, Pecuária e Abastecimento. Regras para Análise de Sementes. Ministério da Agricultura, Pecuária e Abastecimento. Secretaria de Defesa Agropecuária. Brasília, DF: Mapa/ACS, 2009. 398p. 
CRUZ, S. C. S. et al. Cultivo de soja sob diferentes densidades de semeadura e arranjos espaciais. Revista de Agricultura Neotropical, Cassilândia-MS, v. 3, n. 1, p. 1-6, 2016.

EMBRAPA. Sistema brasileiro de classificação de solos. 3. ed., rev. e ampl. Rio de Janeiro, 2013. 353 p.

FERREIRA, Daniel Furtado. Sisvar: a computer statistical analysis system. Ciência e Agrotecnologia, v. 35, n. 6, p. 1039-1042, 2011.

FÁVERO, Fernando; LANA, Maria do Carmo. Redução de haste verde e retenção foliar na soja em razão de maior disponibilidade de nitrogênio pelo tratamento de sementes. Revista Brasileira de Ciência do Solo, v. 38, p. 1432-1438, 2014.

GOOGLE EARTH PRO. Fonte de imagens (2014). Acesso em: 15 out. 2015.

HEIFFIG, L.S. et al. Fechamento e índice de área foliar da cultura da soja em diferentes arranjos espaciais. Bragantia, Campinas, v.65, n.2, p.285-295, 2006.

MINISTÉRIO DA AGRICULTURA, PECUÁRIA E ABASTECIMENTO (MAPA). Disponível em: $<$ http://www.agricultura.gov.br/vegetal/culturas/soja>. Acesso em: 22 de outubro de 2015.

MOTA, F. S.et al. Zoneamento agroclimático do Rio Grande do Sul e Santa Catarina. Porto Alegre: Ministério da Agricultura, Departamento Nacional de Pesquisa Agropecuário do Sul, 1970.

OLIVEIRA JUNIOR, A. de, et al. Produtividade de soja em resposta ao arranjo espacial de plantas e a adubação nitrogenada associada a fertilização foliar. Londrina, PR. 2013.

Disponível em: <http://ainfo.cnptia.embrapa.br/digital/bitstream/item/88690/1/Produtividade-de-sojaem-resposta-ao-arranjo-espacial-de-plantas-e-a-adubacao-nitrogenada-associada-afertilizacao-foliar.pdf>. Acesso em: 16 mai. 2016.

POTAFOS. Associação Brasileira para Pesquisa da Potassa e do Fosfato. Como a planta de soja se desenvolve. Piracicaba, SP. 2000. Disponível em: <http://brasil.ipni.net/ipniweb/region/brasil.nsf/0/9EB3E1289BF2532B83257AA0003BF 72A/\$FILE/Como\%20a\%20Planta\%20da\%20Soja\%20Desenvolve.pdf> Acesso em: 20 mai. 2016.

PROCÓPIO, S.O.,et al. Semeadura em fileira dupla e espaçamento reduzido na cultura da soja. Agro@mbiente On-line, v. 8, n. 2, p. 212-221, maio-agosto, 2014.

SCHIDLOWSKI, Lucas Leonardo. Efeito do espaçamento e população de plantas na morfologia das plantas de soja. Paraná, 2012. Disponível em: <http://revistas.utfpr.edu.br/dv/index.php/CCT_DV/article/viewFile/1011/584>. Acesso em: 09/11/2015.

SEDIYAMA, T. Tecnologias de produção e usos da soja. Londrina: Macenas, 2009. p. 314.

SILVA, A.et al. Desempenho agronômico de cultivares de soja sob diferentes densidade de plantio. In: CONGRESSO BRASILEIRO DE SOJA, 7., MERCOSOJA, 2015, Florianópolis. Tecnologia e mercado global: perspectivas para soja: Anais... Londrina: Embrapa Soja, $2015 . \quad$ Disponível em: 
<http://www.alice.cnptia.embrapa.br/alice/handle/doc/1019690>. Acesso em: 16 mai. 2016.

SOCIEDADE BRASILEIRA DE CIÊNCIA DO SOLO. Manual de adubação e de calagem: para os estados do Rio Grande do Sul e de Santa Catarina. 10. ed. Porto Alegre: [s.n.], 2004. 394 p. 